\title{
Iodine deficiency in UK women of child-bearing age
}

\author{
Margaret Rayman, Michelle Sleeth, Alan Walter and Andrew Taylor \\ University of Surrey, Guildford, Surrey, UK
}

Iodine deficiency in pregnant women can lead to an inadequate supply of thyroid hormones to the fetus resulting in impaired fetal brain development, reduced intelligence scores and impaired motor skills in the offspring of deficient women ${ }^{(1)}$. The importance of adequate iodine intake in pregnancy is such that WHO recommendations of $150 \mu \mathrm{g} / \mathrm{d}$ for non-pregnant adults are increased to $250 \mu \mathrm{g} / \mathrm{d}$ in pregnancy ${ }^{(2)}$. Although the UK is normally considered to be iodine sufficient ${ }^{(3)}$, concern has been expressed recently about the iodine status of UK women ${ }^{(4)}$.

A cross-sectional pilot study was therefore undertaken in thirty-one women of child-bearing age (median age 23 years) to investigate the iodine status of Surrey women. Urine collections $(24 \mathrm{~h})$ were obtained and their total volume measured. Iodide concentration was measured using inductively-coupled plasma MS. Total $24 \mathrm{~h}$ iodide excretion was calculated and used to assess the individual risk of deficiency. Daily iodine intake was calculated assuming that the $24 \mathrm{~h}$ urinary iodide excretion represents $92 \%$ of daily iodine intake ${ }^{(5)}$.

The Figure shows the $24 \mathrm{~h}$ iodide excretion for each subject and the categorisation of iodine status according to Thomson et al. ${ }^{(6)}$ and Als et al. ${ }^{(7)}$. One subject $(3.2 \%)$ was classified as moderately deficient, eight $(25.8 \%)$ had mild deficiency, ten $(32.3 \%)$ had marginal iodine status and the remaining twelve subjects $(38.7 \%)$ had adequate iodine status. The median total $24 \mathrm{~h}$ iodide excretion was $140.5 \mu \mathrm{g}$, categorising the group as a whole as having marginal iodine status. Calculation of iodine intake (extrapolated from urinary iodide excretion) indicated that $48 \%$ did not meet the WHO adult requirement of $150 \mu \mathrm{g} / \mathrm{d}, 42 \%$ had an intake below the UK reference nutrient intake and $87 \%$ would not meet the $250 \mu \mathrm{g} / \mathrm{d}$ WHO intake requirement for pregnancy ${ }^{(2)}$.

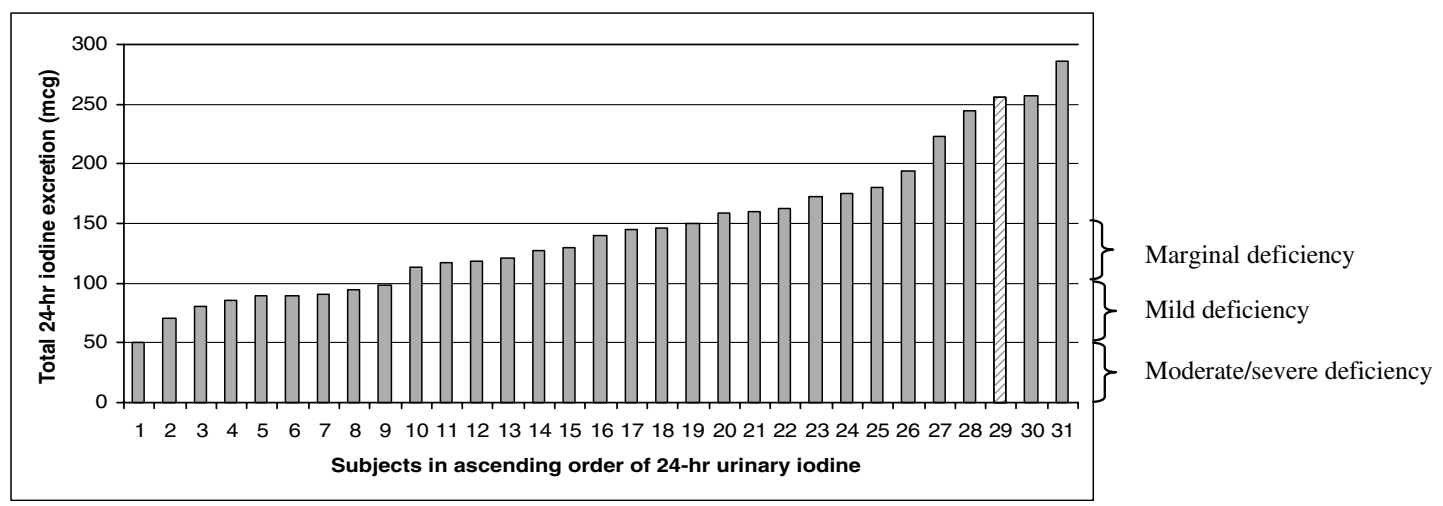

Figure. The $24 \mathrm{~h}$ urinary iodide excretion for Surrey women of child-bearing age and iodine deficiency classification ${ }^{(6,7)}$. ( $\left.\nabla\right)$, Subject took iodine-containing supplement.

The findings of the present small study give cause for concern as approximately $30 \%$ of individuals were classified as mildly to moderately iodine deficient. This finding could have serious consequences if these women were to become pregnant. Various limitations of the study (selection of subjects and season) suggest that this outcome is likely to be a best-case scenario. It may be prudent to advise all pregnant women to increase their intake of iodine-rich foods during pregnancy or to include an iodine supplement in order to minimise potentially adverse effects on the fetus.

1. Haddow JE, Palomaki GE, Allan WC et al. (1999) N Engl J Med 341, 549-555.

2. WHO Secretiariat (2007) Public Health Nutr 10, Suppl. 12a, 1606-1611.

3. Lee SM, Lewis J, Buss DH, Holcombe GD \& Lawrance PR (1994) Br J Nutr 72, 435-446.

4. Kibirige MS, Hutchison S, Owen CJ \& Delves HT (2004) Arch Dis Child Fetal Neonatal Ed 89, F436-F439.

5. Department of Health (1991) Dietary Reference Values (DRVs) for Food Energy and Nutrients in the UK. Report on Health and Social Subjects no. 41. London: The Stationery Office.

6. Thomson CD, Colls AJ, Conaglen JV, Macormack M, Stiles M \& Mann J (1997) Br J Nutr 78, 901-912.

7. Als C, Minder C, Willems D, Van Thi HV, Gerber H \& Bourdoux P (2003) Eur J Clin Nutr 57, 1181-1188. 